\title{
A competition between flowers and chocolate: Consumer perception on the utility of flower gifts for Valentine's Day from the perspective of perfect gift theory
}

\author{
Li-Chun Huang \\ Department of Bio-Industry Communication and Development, National Taiwan University, Taipei, Taiwan
}

\begin{abstract}
Summary
Objectives - Even though chocolate is one of the strongest alternatives for flowers to compete in the market of romantic Valentine's gift giving, the competitiveness of fresh flowers relative to chocolate as Valentine's romantic gifts is rarely investigated in academics. This study addresses this deficiency by clarifying the following questions from the perspective of perfect gift theory: 1) What is the utility of flowers as a romantic Valentine's gift in comparison to chocolate? 2) How does the perceived utility of those two alternatives influence consumers' evaluation toward the appropriateness of giving flowers as a romantic Valentine's gift? Methods - Questionnaires were used as the instrument for data collection. Samples were recruited with a stratified random sampling strategy for increasing the generalizability of the sample. As a result, 444 valid questionnaires were gained. The statistical analyses of ANOVA and multiple regression analysis were processed to achieve the goals of this study. Results - This study revealed that three criteria, i.e., "giver's self-identity", "expressing love", and "practical value", significantly influence consumers' evaluation on buying flowers as a romantic Valentine's gift. Furthermore, the utility of flowers in "giver's self-identity" had a marginal effect on preventing consumers from buying chocolate as a romantic Valentine's gift. Conclusion - The study results imply that "hierarchical value positioning" and "personalization" can be the strategies for the florists.
\end{abstract}

Keywords

ANOVA, consumer schema, gift giving, regression analysis, Valentine's Day

\section{Introduction}

Valentine's Day is the biggest holiday for selling fresh flowers as gifts, as well as the most important occasion for generating the total annual revenue of fresh flowers (Society of American Florists, 2012). Approximately 30\% of the transactions in the global floral industry happen during Valentine's Day, sharing 28\% of the dollar volume of all holiday transactions, while Christmas comes first (29\%) and Mother's Day comes third (24\%) (Gaille, 2019). Men are the main consumers who buy flowers for Valentine's Day. Over $70 \%$ of men buy flowers for romantic reasons (Society of American Florists, 2012).

\section{Significance of this study}

What is already known on this subject?

- Valentine's Day is the biggest holiday for selling fresh flowers as gifts, and florists contribute their efforts in advertising flowers as a "love" gift to resist competition from the alternatives, in particular the strongest competitor for flowers - chocolates.

\section{What are the new findings?}

- Consumer perceived utilities of "giver's self-identity", "expressing love", and "practical value" drive consumers to buy flowers as a romantic Valentine's gift, and whether the floral gift can convey givers' love to the receivers carries greater weight in that driving. However, whether the floral gift can help the givers to identify themselves to the receivers is the only factor that might depress consumers' decision for buying chocolate as a romantic Valentine's gift.

What is the expected impact on horticulture?

- Florists are facing severe competition for selling flowers as romantic Valentine's gifts. Based on the findings, this study provides two strategies, namely, "hierarchical value positioning" and "personalization", for the florists to gain the competition in the market of Valentine's romantic gift giving.

Valentine's Day is a holiday associated with the culture of gift giving for showing love and caring. The culture of Valentine's Day originates from Western countries, but has spread to Eastern countries, e.g., Japan, South Korea, Singapore, Taiwan, etc. The average annual sales volume of Valentine's Day gifts in Taiwan is about US\$ 118.8 million (Eastern Online, 2006). Flowers rank third, after apparel and chocolate, as the favorite romantic gift purchases in Taiwan for Valentine's Day (Eastern Online, 2005). For the consumers in Taiwan, the decision of purchasing fresh flowers as a romantic gift for Valentine's Day is influenced by the development stage of their romantic relationship, as well as by their affection and satisfaction in the relationship. They were more likely to buy their intimate partners fresh flowers when they perceived that their personality need of being loved was fulfilled in the relationship, or they have strong passionate about that relationship (Lai and Huang, 2013).

Flowers have been imbued with the symbolic meanings of love, passion and social status, so they have become a very popular gift for Valentine's Day (Andrei, 2020; Close 
and Zinkhan, 2006; Seaton, 2012). However, florists are facing a very intensive challenge in selling flowers as romantic Valentine's gifts because many alternatives, such as candy, in particular chocolate, jewelry, dining out, clothing, etc., are available on the market to compete for consumers' choice (Allen, 2014; IBIS World, 2014). Among those alternatives, chocolate is one of the strongest competitors for flowers (IBIS World, 2014). The competition between the two is very intense. For example, when surveyed about the gift choice for loved ones for Valentine's Day, nearly $48.7 \%$ of consumers indicated that they buy candy, and $37.3 \%$ reported buying fresh flowers, as gifts (Allen, 2014). The intense competitiveness between flowers and chocolate can also be demonstrated by their sales volume. In the case of the United States, fresh flowers account for about $8.5 \%$ of the total sales volume of Valentine's gifts, and candy accounts for $13.7 \%$, of which chocolate makes up around 75\% (IBIS World, 2014). In Japanese culture, flowers are even replaced by chocolate as the typical gift to say love on Valentine's Day (Iwata, 2014). The consumption of chocolate in Asia is increasing; it shares about $20 \%$ of the global chocolate market. On average, about $\$ 400$ million of chocolate is purchased on Valentine's Day in global, accounting for $5 \%$ of the total sales of the chocolate industry (Gaille, 2017).

Gifts are an instrument for social communication. A diverse range of objects, tangible or intangible, can be used for gifts, including time, service or money (Belk and Coon, 1993; Joy, 2001). For the giver, what is selected as gifts is based on several cues, including the relationship between the dyad of giver and receiver, the occasion of gift giving, and particularly giver's intention for the receiver. On the other side, the receiver interprets giver's intention via what the gift is, and decides whether to accept or reject the gift. The decision of acceptance vs. rejection implies receiver's agreement or rejection on giver's intention (Banks, 1979; Schwartz, 1967). Thus, via the process of gift giving, the intention is communicated between the dyad of giver and receiver (Schwartz, 1967).

Valentine's Day is an important day for many lovers in terms of maintaining their romantic relationship, since this holiday drives them to foster expectations for their lovers, as well as to cultivate an opportunity for their lovers to demonstrate their love in return. If their expectation is not satisfied or the love cannot be proved, disappointment may happen and the relationship may falter (Morse and Neuberg, 2004). Therefore, investigation into the utility of flowers for the lovers to communicate their love can be helpful for the floral industry's goal of selling flowers as "love gifts". Clarke (2007) suggested that a successful gift is characterized by the features of surprise, suspense, sacrifice, and sharing. Based on Belk's theory of the perfect gift (Belk, 1996), there are six characteristics for a gift to maximize its utility in gift giving, namely "sacrifice", "altruism", "luxury", "appropriateness", "surprise" and "delight". Each of these features has its function in enhancing the value of gifts. For example, "surprise" makes the gift more enjoyable and memorable for the receiver since the gift is unexpected by the receiver and reflects the spontaneity of the giver in the relationship (Areni et al., 1998). "Sacrifice" reveals the cost in money, time or psychic efforts contributed by the giver for finding or making the gift; it reflects the importance of the receiver in the giver's mind, and therefore makes the gift more holy and treasured by the receiver (Areni et al., 1998; Belk, 1979). However, which characteristic is more important for the utility of a gift depends on the characteristics of the giver, receiver and relationship. Givers usually decide what to give based on their intentions and the characteristics of receivers, in order to maximize the efficiency of gift giving (Larsen and Watson, 2001; Ward and Broniarczyk, 2011). Even though most of the literature on perfect gifts emerges from the perspective of Western cultures, it has been found that individuals in Eastern cultures have a similar pattern of reactions to perfect gifts, in that they perceive a perfect gift as one with surprise and sacrifice, which is symbolic to the relationship, and the most memorable (Minowa and Gould, 1999).

As chocolates are one of the strongest competitors for flowers in the market of Valentine's romantic gifts (IBIS World, 2014; Mäkelä et al., 2019), the competitiveness of flowers relative to chocolate is rarely investigated systematically, which limits florists' knowledge base for developing efficient marketing strategies to sell flowers as a love gift for the Valentine's Day. This study was addressed for this deficiency by assessing the following questions from the perspective of perfect gift theory: 1) What is consumers' schema for a perfect romantic Valentine's gift? 2) What is the utility of flowers in comparison to chocolate in terms of consumers' schema for a perfect romantic Valentine's gift? 3) When facing the choice between fresh flowers and chocolate, how does consumers' perception in that utility of flowers and/or chocolate influence consumers' evaluations toward the appropriateness of giving flowers as a romantic Valentine's gift?

Consumer schema for a product category represents consumers' cognitive structure and knowledge about the context, characteristics, or attributes for that object category. It influences the formation of consumers' expectations, as well as how the product information is organized, interpreted and memorized by consumers, and therefore influences consumers' evaluation and preference for a product (Davvetas and Diamantopoulos, 2016; Halkias, 2015; Meyers-Levy and Tybout, 1989; Stayman et al., 1992). That is, consumers' product category schema serves as a diagram, base, or guideline for consumers to make an evaluation of a product. Findings from this study can provide knowledge about consumers' conceptual frame for the utility of flowers, as well as the possible trade-off mechanism for consumers' purchase choice between flowers and chocolate, in the setting of Valentine's romantic gift giving, which is beneficial for florists to develop efficient strategies to increase their competitiveness in the market of Valentine's romantic gifts.

\section{Materials and methods}

\section{Questionnaire development}

Questionnaires were developed as the instrument for data collection. For increasing the validity of the questionnaire scales, the questionnaires were composed based on the results of four focus group interviews and literature reviews. At first, four focus groups were held to explore consumers' schema for perfect romantic gifts for Valentine's Day. Subjects in the focus group interview were recruited through advertising on the PTT Bulletin Board System, which is the most popular social media in Taiwan, with over one million registered users (PTT, 2016). As a result, seven females and 16 males from multiple socio-demographic backgrounds participated in the interviews. The dynamics of group interaction in a focus group interview increase participants' willingness to share their thoughts or opinions, allowing the researcher to analyze subjects' cognitive structure formed from their real life experience about the typicality or characteristics of perfect romantic Valentine's gifts (Kitzinger, 1994; Rabiee, 2004). In total, 14 criteria profiling what makes a perfect 
TABLE 1. The variables cited from focus group interviews and literature reviews for developing the questionnaire scales measuring consumer schema for the perfect romantic Valentine's gifts.

\begin{tabular}{|c|c|}
\hline Variables & Citation source \\
\hline Durable & Focus group \\
\hline A surprise to the receiver & Focus group; Belk (1996); Schiffman and Cohn (2009) \\
\hline Practical & Focus group; Schiffman and Cohn (2009) \\
\hline Affordable & Focus group; Rugimbana et al. (2003); Schiffman and Cohn (2009) \\
\hline Special for the receiver & Focus group; Belk and Coon (1993); Otnes et al. (1994); Schiffman and Cohn (2009) \\
\hline Romantic & Focus group \\
\hline Expressing love to the receiver & $\begin{array}{l}\text { Focus group; Close and Zinkhan (2006); Otnes et al. (1994); Rugimbana et al. (2003); } \\
\text { Schiffman and Cohn (2009) }\end{array}$ \\
\hline Expressing appreciation to the receiver & Focus group \\
\hline Needed by the receiver & $\begin{array}{l}\text { Focus group; Belk (1996); Belk and Coon (1993); Rugimbana et al. (2003); } \\
\text { Schiffman and Cohn (2009) }\end{array}$ \\
\hline Representation of Valentine's Day & Focus group; Otnes et al. (1994); Rugimbana et al. (2003); Schiffman and Cohn (2009) \\
\hline Could be shared with each other & Focus group; Close and Zinkhan (2006) \\
\hline Valuable & Belk and Coon (1993); Schiffman and Cohn (2009) \\
\hline $\begin{array}{l}\text { Representing the development stage of the } \\
\text { romantic relationship }\end{array}$ & Belk and Coon (1993); Rugimbana et al. (2003) \\
\hline Display the sense of the giver & Belk and Coon (1993) \\
\hline Display the socioeconomic status of the giver & Belk and Coon (1993); Rugimbana et al. (2003) \\
\hline Announcing the relationship to outsiders & Chen and $\mathrm{Kim}(2013)$ \\
\hline Luxury & Belk (1996) \\
\hline Rare & Focus group \\
\hline Fashionable & Focus group \\
\hline Easy to get & Focus group \\
\hline
\end{tabular}

romantic gift for Valentine's Day were found from the interviewees (Table 1). After that, factors that have been reported to be critical to influence consumers' gift selection or as essential criteria for a perfect gift were cited from literature (Belk, 1996; Close and Zinkhan, 2006; Otnes et al., 1994; Rugimbana et al., 2003), and they were integrated with those 14 criteria to be developed into the questionnaires (Table 1). The questionnaires were used to clarify consumers' schema for a perfect romantic gift for Valentine's Day, as well as to evaluate consumers' perception of the utility of flowers and chocolate for being a romantic Valentine's gift. All the scales were designated in a 5-point Likert scale $(5=$ strongly agree, 4 = agree, 3 = neutral, 2 = disagree, 1 = strongly disagree).

Consumers' perceived appropriateness of giving flowers as a romantic gift for Valentine's Day was also measured on a 5-point Likert scale with multiple questions (e.g., "Flowers are an appropriate gift for Valentine's Day", "Flowers are a good gift for Valentine's Day", and "Flowers are a superior gift for Valentine's Day" ). Subjects' socio-demographics, including age, education, occupation and income, were also recorded with the questionnaires.

\section{Questionnaire survey}

The likelihood of celebrating Valentine's Day and the amount of money spent on the significant other for this holiday tends to decline after the age of 55 years (Lee, 2014). So this study defined the male adults aged from 18 to 55 years old as the survey target for achieving the objectives of this study.

Subjects were recruited with a stratified random sampling strategy for recruiting the subjects across the different lifestyles of urban and non-urban living regions that increased the generalizability of the sample. At first, three administrative districts or towns were randomly selected from each of the cities, suburban cities, and counties which were randomly selected from different geographic regions of Taiwan. The subjects were then sampled from the public sites of those selected administrative districts or towns with a systematic sampling strategy that every third male was selected and asked by the survey staff about their qualification and willingness to participate in the questionnaire survey. The survey took place from 10 July to 10 Sep. 2013, and the questionnaires were answered in a self-administered form. Most of the subjects spent 15 minutes to complete it and received a gift, retailed at the price of about US\$ 4 , as a reward.

The total sample size was determined with Dillman's formula such that at least 384 subjects were needed to maintain the sampling error at an acceptable level of $\alpha=5 \%$ (Dillman, 2000 ), based on the population size of the male adults aged from 18 to 55 years old in Taiwan (DGBAS, 2011). Numbers of subjects recruited from each city, suburban city, or county were determined by the ratio of the male population aged from 18 to 55 years old. In total, 490 questionnaires were collected, 444 of which were valid for the statistical analysis. Forty six questionnaires were invalid due to the problems of being incomplete or being filled out by the consumers who were not in the age range targeted.

\section{Statistical analysis}

All the statistical analyses were processed with SPSS (V. 20; IBM Corp., Armonk, NY). The demographic distribution of the sample was profiled with descriptive statistics, and the underlying dimensionality of consumers' schema for a perfect romantic gift on Valentine's Day was analyzed with factor analysis (Hair et al., 2010; Johnson and Wichern, 2002; Kline, 2014). The scale reliability for each extracted factor underlying the structure of consumer schema for a perfect romantic Valentine's gift was measured in Cronbach's 
$\alpha$ (Cronbach, 1951; Tavakol and Dennick, 2011). After confirmation of scale reliability, the extracted factors were then applied as the basis for evaluating consumers' schema for a perfect romantic gift for Valentine's Day, as well as for consumers' evaluation regarding the utility of flowers and chocolate working as a romantic gift for Valentine's Day. Pairwise comparison among these three evaluations was analyzed with the statistical analysis of ANOVA in repeated measures (Girden, 1992; Weinfurt, 2000).

As purchase choice is an outcome of a trade-off over the pros and cons of alternatives, the influence of the perceived gift utility of flowers and chocolate on consumers' evaluation toward the appropriateness of these two alternatives as a romantic gift for Valentine's Day was evaluated with multiple linear regression analysis. Subjects' socio-demographics, i.e., age, education, occupation and income, were recoded into dummy variables and entered as controlling variables in the regression analysis. The statistical results of the regression analysis allow the researcher to understand the competition between flowers and chocolate in more depth, since they imply possible trade-off behaviors as consumers choose between flowers and chocolate for a romantic gift when Valentine's Day comes.

\section{Results and discussion}

\section{Profile of the sample}

Most participants were aged from 18 to 25 years old (37.8\%), and their highest education level was mostly at a

TABLE 2. The distribution of subjects' socio-demographics.

\begin{tabular}{lc}
\hline Demographics & $\begin{array}{c}\text { Percentage } \\
(\%)\end{array}$ \\
\hline Age & \\
18-25 & 37.8 \\
$26-35$ & 34.1 \\
$36-45$ & 15.3 \\
46-55 & 10.8 \\
\hline Education & \\
Junior high & 1.1 \\
Senior high & 18.4 \\
College/university & 59.0 \\
Graduate school & 21.5 \\
\hline Occupation & \\
Agriculture, forestry, fishery, and animal husbandry & 1.8 \\
Manufacturing & 8.8 \\
Business/service & 37.4 \\
Civil servant, military service, and education & 14.7 \\
Students & 29.7 \\
Retired & 0.2 \\
Housekeeping & 0.2 \\
Others & 7.0 \\
\hline Monthly income (NTDz) & \\
NTD 20,000 or less & 31.2 \\
NTD 20,001-40,000 & 34.1 \\
NTD 40,001-60,000 & 18.5 \\
NTD 60,001-80,000 & 9.3 \\
NTD 80,001-100,000 & 4.3 \\
More than NTD 100,000 & 2.7 \\
\hline
\end{tabular}

zNew Taiwanese Dollar, 1 NTD $=0.0289$ EUR. college degree (59.0\%). As for the occupation distribution, most of the participants (37.4\%) had a job in business or a service industry. Participants' average monthly income was mostly (52.6\%) in the range of NT\$20,001 to NT\$60,000 (1 NTD $\fallingdotseq 0.0289$ EUR). The details of subjects' demographic characteristics are displayed in Table 2.

\section{Consumers' schema for perfect romantic Valentine's gifts}

Factor analysis was run to analyze consumers' schema for perfect romantic Valentine's gifts. Before the factor analysis, the appropriateness of the data matrix for applying factor analysis was confirmed with a significant Bartlett's test of sphericity $\left(\chi^{2}=2,540.20, P=0.000\right)$ and a satisfactory level of KaiserMeyer-Olkin measure of sampling adequacy (MSA=0.82).

The statistical results of factor analysis with the principal component extraction method and quartimax rotation indicated that consumers' schema for a perfect romantic Valentine's gift could be summarized into three structured factors, accounting for $53.55 \%$ of the total variance of the data matrix. The final component variables for each extracted factor was determined by the following criteria: 1) a variable with an absolute value of its factor loading less than 0.4 is deleted; 2) a variable with several high factor loadings is deleted; 3) a variable that does not load on any factor is deleted (Hair et al., 2010). As a result, three factors were generated from the factor analysis. These three factors were named as "giver's self-identity", "expressing love" and "practical value", according to the context of their component variables. The internal consistency of the component variables for each of these three factors was at a qualified level, with Cronbach's $\alpha$ of $0.82,0.71$, and 0.66 , respectively. The structure and reliability of the component variables for these three factors were presented in Table 3.

\section{The utility of flowers as a romantic Valentine's gift in comparison to chocolate}

The consumer schema explored in this study, as described above, summarized consumers' cognition and knowledge about a perfect romantic Valentine's gift. Theoretically, those factors will serve as a reference frame for consumers to judge whether a product can be identified as a perfect romantic Valentine's gift (Halkias, 2015; Meyers-Levy and Tybout, 1989; Stayman et al., 1992). Thus, in this study consumers' evaluation regarding the utility of flowers vs. chocolate for being a romantic Valentine's gift was measured based on these three criteria. Repeated measures ANOVA was then applied to assess whether the perceived utility of flowers differs from that of chocolate and/or consumers' schema, in order to evaluate the extent to which consumers perceive flowers as a perfect romantic gift for Valentine's Day, and what is the difference from chocolate. The findings are described in the following:

1. Factor 1 "Giver's self-identity". The first factor was named "giver's self-identity". The statistical results of repeated measures ANOVA with Greenhouse-Geisser correction indicated that the measure of flowers as a romantic gift on the utility of "giver's self-identity" was significantly better than that of chocolate, even though both were behind the levels expected by consumers for a perfect romantic Valentine's gift $(P=0.000)$, as presented in Table 4 .

Based on its component variables, this factor refers to consumers' thoughts that a perfect romantic gift should be "luxurious", "stylish", "valuable", and "rare", in order to "display the taste of the giver" and "imply the socio-demographics of the giver". At first glance, these component variables 
TABLE 3. Component variables and scale reliability of factors measuring consumers' schema for a perfect romantic Valentine's gift.

\begin{tabular}{|c|c|c|c|c|c|c|c|}
\hline \multirow{2}{*}{ Utility factors ${ }^{2}$} & \multirow{2}{*}{ Component variables } & \multirow{2}{*}{ Mean } & \multirow{2}{*}{ SD } & \multirow{2}{*}{$\begin{array}{l}\text { Factor } \\
\text { loadings }\end{array}$} & \multicolumn{3}{|c|}{ Cronbach's a } \\
\hline & & & & & Perfect gifts & Flowers & Chocolate \\
\hline \multirow{6}{*}{$\begin{array}{l}\text { Giver's } \\
\text { self-identity }\end{array}$} & Implies socio-economic status of givers & 2.89 & 0.983 & 0.77 & 0.82 & 0.84 & 0.88 \\
\hline & Luxury & 2.61 & 0.899 & 0.76 & & & \\
\hline & Fashionable & 3.05 & 0.909 & 0.72 & & & \\
\hline & Valuable & 2.81 & 0.891 & 0.71 & & & \\
\hline & Rare & 2.91 & 0.967 & 0.70 & & & \\
\hline & Displays taste of givers & 3.48 & 0.938 & 0.64 & & & \\
\hline \multirow{4}{*}{$\begin{array}{l}\text { Expressing } \\
\text { love }\end{array}$} & Romantic & 3.93 & 0.759 & 0.81 & 0.71 & 0.78 & 0.72 \\
\hline & Expresses givers' love to receivers & 4.10 & 0.724 & 0.79 & & & \\
\hline & Representative of Valentine's Day & 3.68 & 0.881 & 0.64 & & & \\
\hline & Surprises receivers & 4.43 & 0.677 & 0.59 & & & \\
\hline \multirow{3}{*}{$\begin{array}{l}\text { Practical } \\
\text { value }\end{array}$} & Practical & 3.90 & 0.810 & 0.83 & 0.65 & 0.75 & 0.68 \\
\hline & Durable & 3.75 & 0.851 & 0.69 & & & \\
\hline & Needed by the receiver & 4.06 & 0.824 & 0.62 & & & \\
\hline
\end{tabular}

${ }^{z}$ Extracted by factor analysis with principal component extraction method and quartimax rotation.

seem to refer to two independent issues according to their wording, one about the monetary value of the gift and the other about the personal traits of the giver. In fact, these two issues are closely related in the social behavior of gift giving. An expensive or rare gift not only allows givers to show their recognition of the relationship with receivers (Banks, 1979; Belk, 1979; Otnes et al., 1994), but also displays givers' wealth, social status, taste, and social role to receivers (Belk and Coon, 1993; Schwartz, 1967). For example, givers may give visibly expensive or artistic gifts to gain a favorable impression of being generous or tasteful from receivers (Belk, 1979). As wealth, social background, and personality are common traits that influence women's preference in mate selection (Buss and Barnes, 1986; Fisman et al., 2006; Göz et al., 2018; Sprecher et al., 1994; Zheng, 2017), it is reasonable to expect that gifts that can help in communicating givers' social background and personality to receivers will be favored. 2. Factor 2 "Expressing love". Another criterion in consumers' mind for a perfect romantic Valentine's gift is "expressing love" for the receiver. A subsequent Bonferroni post hoc test after a significant statistical result from the analysis of repeated measures ANOVA with Greenhouse-Geisser correction $(P=0.000)$ indicated that consumer evaluations toward flowers and chocolate on the utility of "expressing love" for the receiver were significantly lower than the level that consumers expect for a perfect romantic Valentine's gift, even though flowers have a long history symbolizing love in both Western and Eastern cultures (Ziegler, 2007). However, flowers were perceived to be better than chocolate on this utility, as presented in Table 4 .

Based on its component variables, this factor refers to consumers' thought that a perfect romantic Valentine's gift should be able to convey givers' love for receivers. This is the characteristic that subjects emphasize most for a perfect romantic Valentine's gift in this study. As Valentine's Day is a holiday for saying "love" (Otnes et al., 1994), it is reasonable to expect that "love for the receiver" is one of the criteria that consumers would emphasize in assessing perfect romantic Valentine's gifts. Actually, love is the most important message that givers want to convey in romantic gift giving, even

TABLE 4. Pairwise comparison between consumers' evaluations toward the utility of flowers and chocolate on the basis of consumers' schema for a perfect romantic Valentine's gift.

\begin{tabular}{|c|c|c|c|c|c|c|c|}
\hline \multirow[b]{2}{*}{ Utility factors } & \multirow[b]{2}{*}{ Gifts } & \multirow[b]{2}{*}{ Means $S^{y, x}$} & \multicolumn{5}{|c|}{ Tests of within-subjects effects ${ }^{z}$} \\
\hline & & & $\begin{array}{l}\text { Type III sum } \\
\text { of squares }\end{array}$ & $\begin{array}{l}\text { Mean } \\
\text { square }\end{array}$ & df & $F$ & $P$ \\
\hline \multirow[t]{3}{*}{ Giver's self-identity } & Perfect gifts & $2.95^{\mathrm{a}}$ & 23.46 & 12.46 & 1.88 & 47.84 & $0.000^{*}$ \\
\hline & Fresh flowers & $2.75^{b}$ & & & & & \\
\hline & Chocolate & $2.63^{c}$ & & & & & \\
\hline \multirow[t]{3}{*}{ Expressing love } & Perfect gifts & $4.03^{a}$ & 84.81 & 42.49 & 1.99 & 163.60 & $0.000^{*}$ \\
\hline & Fresh flowers & $3.63^{b}$ & & & & & \\
\hline & Chocolate & $3.42^{\mathrm{c}}$ & & & & & \\
\hline \multirow[t]{3}{*}{ Practical value } & Perfect gifts & $3.91^{\mathrm{a}}$ & 328.00 & 170.21 & 1.93 & 369.29 & $0.000^{*}$ \\
\hline & Fresh flowers & $2.73^{c}$ & & & & & \\
\hline & Chocolate & $3.04^{b}$ & & & & & \\
\hline
\end{tabular}

z With a Greenhouse-Geisser correction.

y Pairwise comparison adjusted with Bonferroni inequality.

$\times$ Means with different superscript letters within a utility factor were significantly different.

* Significant at $P \leq 0.001$. 
though it may be blended with other motivations (Belk and Coon, 1993; Rugimbana et al., 2003).

3. Factor $\mathbf{3}$ "Practical value". The other essential criterion in consumers' mind for a perfect romantic Valentine's gift was "practical value for the receiver", composed of the component variables of "practical", "durable", and "needed by the receiver". A subsequent Bonferroni post hoc test after a significant statistical outcome from repeated measures ANOVA $(P=0.000)$ indicated that consumer evaluations toward both flowers and chocolate on the utility of "practical value for the receiver" were significantly lower than consumers' expected level for a perfect romantic Valentine's gift. Furthermore, flowers were worse than chocolate on this criterion for being a romantic gift for Valentine's Day (Table 4).

Compared with flowers, chocolate is more competitive on the utility of "practicality". This may not be simply because chocolate is food that is edible and liked by most consumers; in addition, the social meaning of "food sharing" may play a very important role in the competitiveness of chocolate. Previous literature has found that eating together or sharing food is a way of sharing intimacy, so food is just as typical as some conventional activities, such as a date, sex, or closeness, that an intimate couple may expect to have for Valentine's Day (Close and Zinkhan, 2006). Eating together, e.g., snacking or dining out, is a very common mutual activity for intimate couples, and is seen as a love-related routine behavior for humans (Lemieux, 1996). From the perspective of the social psychology of food sharing, chocolate may be an easy way for men to show their intimacy in a relationship. In the focus group interviews held in this study, some subjects reported that when they gave chocolate as a Valentine's gift to their lovers, they received immediate reciprocity in that their lovers shared the chocolate with them at the time of receiving it. They reported that they really enjoyed that immediate reciprocity and the atmosphere of "sharing", and they felt the sharing created a more intimate relationship for them. In sum, chocolate is a gift associated with the social psychology of food sharing that creates an intimate atmosphere for the relationship. In contrast, flowers tend to be an emotional gift to convey the giver's passionate love, and their consumption value for consumers is spiritual. Those factors may distance flowers from the image of "practical".

\section{The gift utility that influences consumers' evaluations toward the appropriateness of giving flowers as a romantic Valentine's gift}

When a gift is needed or liked by the receiver, suitable for the relationship, or fits the occasions, it is perceived as an "appropriate" gift. The social functions of gift giving can go well only when the gift is appropriate. Therefore, "appropriateness" is critical for consumers' gift selection. As indicated by the consumer schema explored in this study, consumers have their norms about the characteristics of a perfect gift for the romantic gift giving of Valentine's Day, namely "giver's self-identity", "expressing love", and "practical value". As flowers are perceived to have the pros and cons on these three features compared with chocolate, another question arises which is critical for efforts to enhance the competitiveness of flowers in the market of romantic Valentine's gifts: as a purchase decision is the outcome of the trade-off over the pros and cons of alternatives (Armstrong et al., 2016), how do the relative advantages and disadvantages based on consumers' schema for perfect romantic Valentine's gifts influence consumers' evaluation toward the appropriateness of flowers and chocolate for being a romantic Valentine's gift? Answers to this can help clarify consumers' trade-off between flowers and chocolate as they face a choice between these two alternatives.

The above question was probed with linear regression analysis in this study. The statistical results indicated that the advantages of flowers on all those three criteria for perfect romantic gifts, as well as the advantage of chocolate on "practical value for the receiver", significantly influenced consumers' perceived appropriateness of giving flowers as a romantic Valentine's gift ( $\alpha=0.05)$, with $51 \%$ of the variance explained (adjusted $R^{2}=0.513$ ). Those effects of foci variables remained significant even controlling for the effect of socio-demographic characteristics. As presented in Table 5, the gift utility of flowers, in terms of "giver's self-identity", "expressing love", and "practical value", had higher weight in influencing consumers' perceived appropriateness for giving flowers as a romantic Valentine's gift. In contrast, the gift utility perceived by consumers for the competitor, i.e., chocolate, tended to come in second (Table 5). Even though consumers' perceived gift utility of chocolate on "practical value" significantly influenced consumers' perception of the appropriateness of giving flowers as a romantic Valentine's gift, the effect is much less than that of consumers' perception of the "practical value" for flowers. A similar effect occurred with chocolate, as indicated by the statistical results presented in Table 5. However, the utility of flowers in showing the giver's self-identity decreased consumers' perceived appropriateness for chocolate. The decreasing effect became insignificant, but at a marginal level $(P=0.051)$, when controlling for the effect of socio-demographic characteristics. This implies that both consumer perception of the flower gift utility of self-identity and consumer evaluation toward the appropriateness of buying chocolate as a romantic Valentine's gift may be influenced by some socio-demographic characteristics. In sum, whether consumers would choose flowers as a romantic Valentine's gift would mostly depend on their evaluation toward the utility of floral gifts, instead of their evaluation toward that of the competitor.

Based on the study findings, this study provides the following strategies for florists to compete with the chocolate merchants as the season of Valentine's comes:

1. Hierarchical value positioning. As indicated by previous studies, even though givers' motivations in romantic gift giving are multiple and complex, "love" is the basic message that most givers would like to demonstrate via Valentine's gifts, no matter whether givers see the gift giving as a pleasure, obligation, or stress (Otnes et al., 1994; Polonsky et al., 2000; Rugimbana et al., 2003). The current study shows that "giver's love for the receiver" is the most emphasized criterion for the measure of perfect romantic Valentine's gifts, and consumers see flowers as superior at this. It implies that the core value of flowers cannot be detached from the function of showing givers' love for receivers when being sold as a romantic Valentine's gift. As Valentine's Day is commercially defined as a holiday for romantic gift giving, many products competing on this market are more or less positioned in the meaning of love. That is, "love" is a product position shared by many alternatives, including flowers and their competitors. Therefore, once "showing love" is positioned as the core value for flowers to compete in the market of romantic Valentine's gifts, florists need to promote their floral gifts not only on what they can do, but also on how much better they can do it compared with the alternatives. Otherwise, the product position of "love gifts" would be too weak to gain any competitiveness for flowers. 


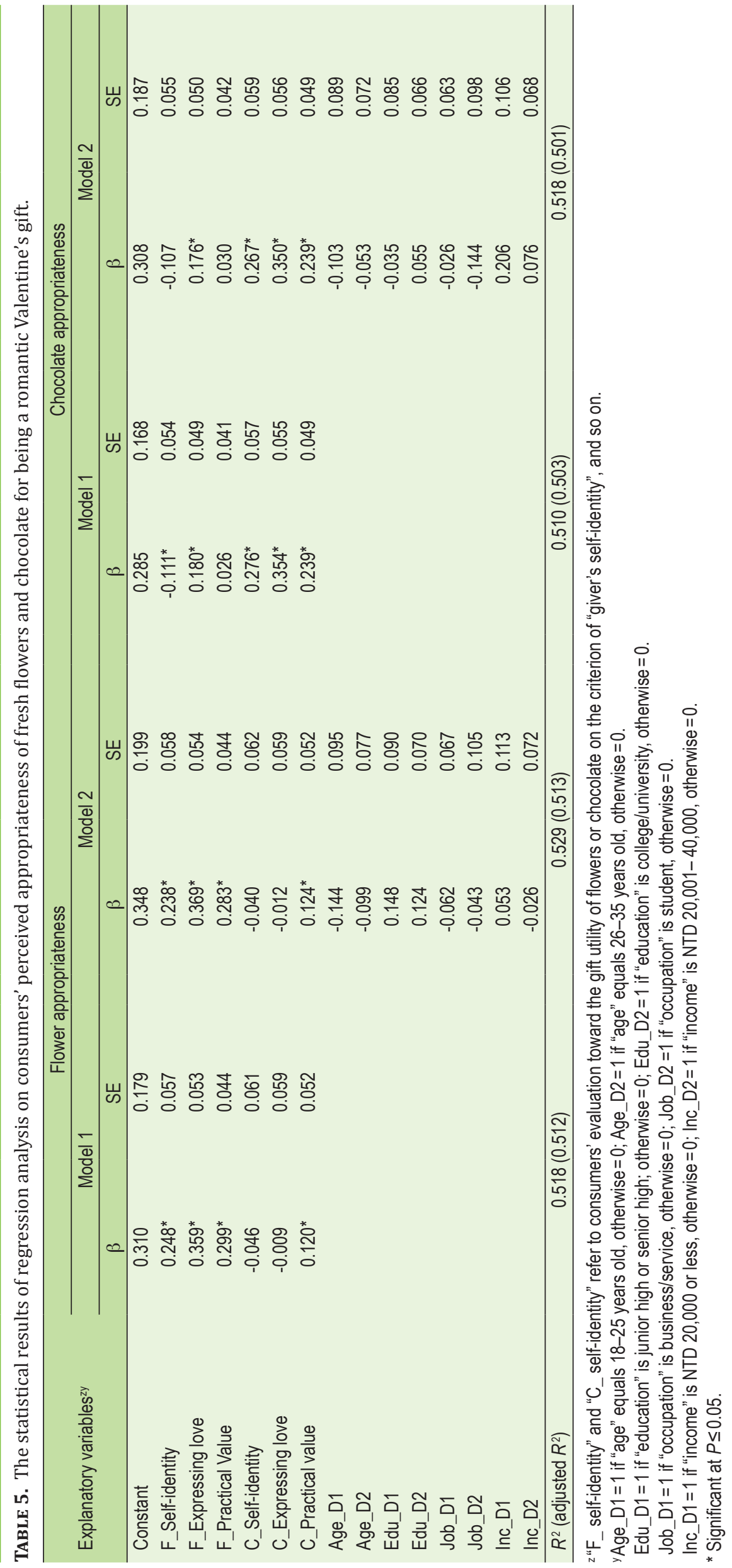


The strategy of setting "giver's self-identity" and "practical value" as supportive product value for floral gifts is proposed based on several reasons, including empowering floral gifts to be more competitive in the market of romantic Valentine's gifts, to satisfy consumers' mixed motivations in romantic gift giving, and to fulfill consumers' needs in gift giving for various conditions. As mentioned above, if only "showing love" is emphasized when promoting flowers as romantic Valentine's gifts, there are many alternatives available on the market to replace floral gifts. Therefore, joint or supportive product value needs to be developed to make floral gifts more defensive and competitive vis-à-vis the alternatives. But why ought it to be the value of giver's self-identity or practical value for the receiver? Since these two factors not only saliently influence consumers' perception of the appropriateness of flowers as gifts, the utility of flowers on showing giver's self-identity might also decrease consumers' perception of the appropriateness of chocolate as gifts. By that theory, givers' motivations in romantic gift giving incorporate multiple purposes, including the motivations of social exchange, economic exchange, and agapic love, i.e., to give cues about givers' personality or social resources, to invest the relationship with the economic value of gifts, or to show givers' pure love (Belk and Coon, 1993; Ward and Broniarczyk, 2011). In other words, as flowers are promoted as romantic gifts, they need to fulfill multiple functions in order to satisfy consumers' multiple purposes in romantic gift giving.

The hierarchical value positioning is also proposed as a tactic to make flowers more flexible to satisfy consumers' needs for various gift giving conditions, such as the conditions of different development stages of a romantic relationship, or givers' psychological attachment orientation toward romantic love. Gift giving in a new romantic relationship is quite different from that in a mature one. In addition to conveying their love or adoration, givers in a new romantic relationship have more need to engage in self-presentation to receivers, in particular to explore their personal traits and social resources, in order to be understood and accepted in the relationship (Ward and Broniarczyk, 2011). It is reasonable to expect those givers to demand more in terms of the value of showing the giver's self-identity when making a purchase choice for a romantic Valentine's gift. Similarly, due to the difference of individuals' attachment orientations to romantic relationships, like anxiety attachment, secure attachment, or avoidant attachment, individuals perceive "love" differently, and reveal different commitment levels to it. As a result, individuals behave differently in romantic gift giving and may see romantic gift giving as an obligation or pleasure. Thus, givers who have different attachment orientations to romantic love may look for different gift values when making a purchase choice for romantic Valentine's gifts (Nguyen and Munch, 2011). As illustrated above, to set "representation of the giver's self-identity", "practical value for the receiver", or both, as the supportive product value can make flowers more flexible in satisfying consumers' needs in various gift giving conditions.

2. Personalization. Even though "giver's self-identity" was not perceived to be as important as "love for receiver" or "practical value for the receiver" for consumers' assessment of the utility of a perfect romantic gift for Valentine's Day, the statistical results of regression analysis indicated that the utility of flowers in terms of showing the giver's self-identity might have a negative impact on the perceived appropriateness of giving chocolate as a romantic Valentine's gift. In oth- er words, as consumers are more likely to perceive flowers as a gift able to represent the giver's personal traits or status, they are more likely to deny the appropriateness of chocolate as a romantic Valentine's gift. This research finding implies that if florists can make floral gifts more personalized for the giver, it would not only enhance consumers' perception for the suitability of flowers, but also weaken consumers' perception for that of chocolate, as considering a romantic gift for Valentine's Day.

Since floral gifts can achieve "giver's self-identity" with two effects for floral gifts in terms of both market competitiveness and defensiveness, as illustrated on the above, "personalization" can be a good product strategy for floral gifts to compete on. In human culture, flowers have been used to display personal traits, namely showing personal characteristics, tastes or social status in various settings, such as gift giving, celebration, or weddings (Ziegler, 2007). The personal traits of givers that are beneficial for a romantic relationship can be blended into the design of floral gifts. Besides the personalization of the giver, the gift utility of showing the giver's self-identity can also be achieved by the personalization for the receiver, i.e., personalizing the floral gift with the receiver's needs or preferences (Belk, 1996). A gift needed or preferred by the receiver is not merely an indicator of the gift utility of "practicality", but also a sign expressing the giver's similarity to or understanding of the receiver (Belk and Coon, 1993; Otnes et al., 1994; Rugimbana et al., 2003; Schiffman and Cohn, 2009), which is important for the longevity of romantic relationships.

\section{Conclusion}

As romantic gift giving on Valentine's Day is an important business sector for the floral industry, the competitiveness of flowers for being a romantic gift needs to be systematically investigated. This study contributes to that and provides several significant findings: (1) By consumers' schema, the utility of a perfect romantic Valentine's gift can be measured with the criteria of "giver's self-identity", "expressing love" and "practical value"; (2) As a romantic gift for Valentine's Day, flowers are perceived to be more competitive on the utility of "giver's self-identity" and "expressing love", but weaker on "practical value ", compared with chocolate; (3) The perceived utility of flowers across all the criteria found in this study for a perfect romantic Valentine's gift influences consumers' judgment about the appropriateness of giving flowers as a romantic gift for Valentine's Day; (4) Even though "giver's self-identity" was not the most emphasized criterion for measuring the utility of a perfect romantic Valentine's gift, consumers' evaluation toward the appropriateness of flowers as a romantic Valentine's gift increased with increased belief that flowers show the giver's self-identity, and it might decrease consumers' evaluation toward the appropriateness of chocolate.

The study results imply the importance of the marketing work of value positioning for increasing the competitiveness of flowers on the gift market of Valentine's. In the first, the product value of flower gifts should cover the entire range of gift utility desired by consumers for a perfect romantic gift, including showing giver's self-identity, conveying giver's love to receiver, and being practical to the receiver, since all those significantly influence consumers' judgment about the appropriateness of buying flowers as a romantic Valentine's gift. However, these product values should be positioned strategically for floral gifts to gain a competitive edge in the market, namely to posit "expressing love" as the core value, 
and both "giver's self-identity" and "practical value" as the supportive value, which is named "hierarchical value positioning" in this study, as discussed above.

Another valuable implication from this study is the double strategical meanings of "giver's self-identity" for flowers to compete with chocolate gifts during Valentine's Day. Florists should design their floral gifts with the attributes that can convey giver's personal traits to the receiver. It would not only enhance buyer's perception of the appropriateness of giving flowers as a romantic Valentine's gift, but might also prevent giver's thought from buying chocolate gifts instead. As discussed, "personalization" can be a good product strategy for floral gifts to compete against chocolate during Valentine's Day.

As analyzed in this study, the symbolism of love and personal traits is important for positioning the product value and market defensive strategy when selling flowers as romantic gifts. It is suggested that future research focus on the socialization process through which consumers learn the symbolism and use of floral gifts. Relevant studies would help the floral industry know the critical sources, such as the media or personnel, that inspire in consumers the preference for or use of flowers as gifts in particular settings, which would be beneficial for promoting flowers as romantic gifts.

\section{Funding}

This study was financially supported by the Ministry of Science and Technology of Taiwan (MOST 104-2410-H-002174-MY2).

\section{References}

Allen, K.G. (2014). Consumers keep budgets in check this Valentine's Day, according to NRF, 3 Nov. 2014. https://nrf.com/media/pressreleases/consumers-keep-budgets-check-this-valentines-dayaccording-nrf.

Andrei, T. (2020). Valentine's Day - Implications for the consumer behavior (Târgu Jiu, Rumania: Constantin Brancusi Univ., Fac. of Economics) Annals - Economy Series 5, 151-157.

Areni, C.S., Kiecker, P., and Palan, K.M. (1998). Is it better to give than to receive? Exploring gender differences in the meaning of memorable gifts. Psychology \& Marketing 15(1), 81-109. https:// doi.org/10.1002/(SICI)1520-6793(199801)15:1<81::AIDMAR6>3.0.CO;2-J.

Armstrong, G., Kotler, P., and Opresnik, M.O. (2016). Marketing: An introduction, $8^{\text {th }}$ edn. (Upper Saddle River, NJ, U.S.A.: Pearson).

Banks, S.K. (1979). Gift-giving: A review and an interactive paradigm. Adv. Consum. Res. 6, 319-324.

Belk, R.W. (1979). Gift-giving behavior. In Research in Marketing, J.N. Sheth, ed. (Greenwich, CT, U.S.A.: JAI Press), p. 95-126.

Belk, R.W. (1996). The perfect gift. In Gift Giving: A Research Anthology, C. Otnes, and R.F. Beltramini, eds. (Bowling Green, $\mathrm{OH}$, U.S.A.: Bowling Green State Univ. Popular Press), p. 59-84.

Belk, R.W., and Coon, G.S. (1993). Gift giving as agapic love: An alternative to the exchange paradigm based on dating experiences. J. Consum. Res. 20(3), 393-417. https://doi.org/10.1086/209357.

Buss, D.M., and Barnes, M. (1986). Preferences in human mate selection. J. Person. Soc. Psychol. 50(3), 559-570. https://doi. org/10.1037/0022-3514.50.3.559.

Chen, J., and Kim, S. (2013). A comparison of Chinese consumers' intentions to purchase luxury fashion brands for self-use and for gifts. J. Intl. Consum. Marketing 25, 29-44. https://doi.org/10.1080/ 08961530.2013.751796.
Clarke, J. (2007). The four 'S's of experience gift giving behaviour. Intl. J. Hospitality Mgt. 26, 98-116. https://doi.org/10.1016/j. ijhm.2005.10.001.

Close, A.G., and Zinkhan, G.M. (2006). A holiday loved and loathed: A consumer perspective of Valentine's Day. Adv. Consum. Res. 33, 356-365.

Cronbach, L.J. (1951). Coefficient alpha and the internal structure of tests. Psychometrika 16(3), 297-334. https://doi.org/10.1007/ BF02310555.

Davvetas, V., and Diamantopoulos, A. (2016). How product category shapes preferences toward global and local brands: A schema theory perspective. J. Intl. Marketing 24(4), 61-81. https://doi. org/10.1509/jim.15.0110.

DGBAS (Directorate-General of Budget, Accounting and Statistics). (2011). Statistics of stationary population. http://eng.dgbas.gov. tw/mp.asp. (accessed November 28, 2011).

Dillman, D.A. (2000). Mail and internet surveys: The tailored design method, $2^{\text {nd }}$ edn. (New York, U.S.A.: Wiley).

Eastern Online. (2005). Analysis on the behavior of Valentine's Day gift giving (Taiwan, Taipei) (in Chinese).

Eastern Online. (2006). Trend analysis of gift market in Taiwan: The change from 2001 to 2006 (Taipei, Taiwan) (in Chinese).

Fisman, R., Iyengar, S.S., Kamenica, E., and Simonson, I. (2006). Gender differences in mate selection: Evidence from a speed dating experiment. Quarterly J. Economics 121(2), 673-697. https://doi. org/10.1162/qjec.2006.121.2.673.

Gaille, B. (2017). 27 Incredible chocolate consumption statistics. https://brandongaille.com/26-incredible-chocolate-consumptionstatistics/. (accessed February 23, 2021).

Gaille, B. (2019). 45 Floral industry statistics and trends. BRANDONGAILLE.COM-small business \& marketing advice. https:// brandongaille.com/45-floral-industry-statistics-and-trends/.

Girden, E.R. (1992). ANOVA: Repeated measures (Newbury Park, CA, U.S.A.: Sage). https://doi.org/10.4135/9781412983419.

Göz, İ., Bahçekapili, H.G., and Yilmaz, O. (2018). Testing evolutionary and cultural theories regarding mate selection in Turkey. Personal. Indiv. Diff. 135, 307-311. https://doi.org/10.1016/j. paid.2018.07.041.

Hair Jr., J.F., Black, W.C., Babin, B.J., and Anderson, R.E. (2010). Multivariate Data Analysis: A Global Perspective, $7^{\text {th }}$ edn. (Upper Saddle River, NJ, U.S.A.: Pearson).

Halkias, G. (2015). Mental representation of brands: A schemabased approach to consumers' organization of market knowledge. J. Product Brand Mgt. 24(5), 438-448. https://doi.org/10.1108/ JPBM-02-2015-0818.

IBIS World (2014). Valentine's Day Sales Up 3.7\% in 2014. http:// www.ibisworld.com/media/2 014/02/05/valentines-daysales-3-7-2014 (accessed November 3, 2014).

Iwata, M. (2014). Chocolate or Flowers on Valentine's Day? http:// blogs.wsj.com/japanrealtime/2014/02/10/chocolate-or-flowerson-valentines-day (accessed November 13, 2014).

Johnson, R.A., and Wichern, D.W. (2002). Applied Multivariate Statistical Analysis, $5^{\text {th }}$ edn. (Upper Saddle River, NJ, U.S.A.: Pearson).

Joy, A. (2001). Gift giving in Hong Kong and the continuum of social ties. J. Consumer Res. 28, 239-256. https://doi.org/10.1086/322900.

Kitzinger, J. (1994). The methodology of focus groups: The importance of interaction between research participants. Sociol. Health \& Illness 16(1), 103-121. https://doi.org/10.1111/14679566.ep11347023. 
Kline, P. (2014). An Easy Guide to Factor Analysis (New York, U.S.A.: Routledge). https://doi.org/10.4324/9781315788135.

Lai, Y.C., and Huang, L.C. (2013). The effect of relationship characteristics on buying fresh flowers as romantic Valentine's Day gifts. HortTechnology 23(1), 28-37. https://doi.org/10.21273/ HORTTECH.23.1.28.

Larsen, D., and Watson, J.J. (2001). A guide map to the terrain of gift value. Psychol. Marketing 18(8), 889-906. https://doi.org/10.1002/ mar.1034.

Lee, I. (2014). Valentine's Day 2014 Consumer analysis. http:// www.business2community.com/consumer-marketing/valentinesday-2014-consumer-analysis-0781894\#JR8eWKf1XZRupEzl.97 (accessed January 19, 2015).

Lemieux, R. (1996). Picnics, flowers, and moonlight strolls: An exploration of routine love behaviors. Psychol. Rpt. 78(1), 91-98. https://doi.org/10.2466/pr0.1996.78.1.91.

Mäkelä, M., Bettany, S., and Stevens, L.J. (2019). Crunch my heart! It falls for you: Carnal-singularity and chocolate gift-giving across language contexts. In Gifts, Romance and Consumer Culture, Y. Minowa, and R.W. Belk, eds. (New York and London: Routledge Interpretive Marketing Research). https://doi.org/10.4324/9781315144658-9.

Meyers-Levy, J., and Tybout, A.M. (1989). Schema congruity as a basis for product evaluation. J. Consum. Res. 16(1), 39-54. https:// doi.org/10.1086/209192.

Minowa, Y., and Gould, S.J. (1999). Love my gift, love me or is it love me, love my gift: A study of the cultural construction of romantic gift giving among Japanese couples. Adv. Consum. Res. 26, 119-124.

Morse, K.A., and Neuberg, S.L. (2004). How do holidays influence relationship processes and outcomes? Examining the instigating and catalytic effects of Valentine's Day. Personal Relationships 11(4), 509-527. https://doi.org/10.1111/j.1475-6811.2004.00095.x.

Nguyen, H.P., and Munch, J.M. (2011). Romantic gift giving as chore or pleasure: The effects of attachment orientations on gift giving perceptions. J. Bus. Res. 64(2), 113-118. https://doi.org/10.1016/j. jbusres.2010.02.006.

Otnes, C., Ruth, J.A., and Milbourne, C.C. (1994). The pleasure and pain of being close: Men's mixed feelings about participation in Valentine's Day gift exchange. Adv. Consum. Res. 21, 159-164.

Polonsky, M.J., Donahay, B., Neal, C., Rugimbana, R., King, T., Bowd, T., and Porter, A. (2000). Motivations for Male Gift Giving on Valentine's Day. ANZMAC 2000 Visionary Marketing for the $21^{\text {st }}$ Century: Facing the Challenge, p. 1000-1004.

PTT. (2016). What is PTT? https://www.ptt.cc/index.html. (accessed September 28, 2016).

Rabiee, F. (2004). Focus-group interview and data analysis. Proc. Nutr. Soc. 63, 655-660. https://doi.org/10.1079/PNS2004399.

Rugimbana, R., Donahay, B., Neal, C., and Polonsky, M.J. (2003). The role of social power relations in gift giving on Valentine's Day. J. Consum. Behav. 3, 63-73. https://doi.org/10.1002/cb.122.

Schiffman, L.G., and Cohn, D.Y. (2009). Are they playing by the same rules? A consumer gifting classification of marital dyads. J. Bus. Res. 62, 1054-1062. https://doi.org/10.1016/j.jbusres.2008.09.012.

Schwartz, B. (1967). The social psychology of the gift. Am. J. Sociol. 73(1), 1-11. https://doi.org/10.1086/224432.

Seaton, B. (2012). The Language of Flowers: A History (University of Virginia Press).

Society of American Florists (2012). Valentine's Day floral statistics. https://safnow.org/aboutflowers/holidays-occasions/valentinesday/valentines-day-floral-statistics/ (accessed November 3, 2012).
Sprecher, S., Sullivan, Q., and Hatfield, E. (1994). Mate selection preferences: Gender differences examined in a national sample. J. Pers. Soc. Psychol. 66(6), 1074-1080. http://dx.doi. org/10.1037/0022-3514.66.6.1074.

Stayman, D.M., Alden, D.L., and Smith, K.H. (1992). Some effects of schematic processing on consumer expectations and disconfirmation judgments. J. Consum. Res. 19(2), 240-255. https:// doi.org/10.1086/209299.

Tavakol, M., and Dennick, R. (2011). Making sense of Cronbach's alpha. Intl. J. Med. Educ. 2, 53-55. https://doi.org/10.5116/ ijme. $4 \mathrm{dfb} .8 \mathrm{dfd}$.

Ward, M.K., and Broniarczyk, S.M. (2011). It's not me, it's you: How gift giving creates giver identity threat as a function of social closeness. J. Consum. Res. 38, 164-181. https://doi.org/10.1086/658166.

Weinfurt, K.P. (2000). Repeated measures analysis: ANOVA, MANOVA, and HLM. In Reading and Understanding More Multivariate Statistics, L.G. Grimm, and P.R. Yarnold, eds. (Washington, DC, U.S.A.: Am. Psychol. Assoc.), p. 317-361.

Zheng, J. (2017). Mate selection and gender reflexivity: The emphasis of gan jue and the emergence of a new generational pattern of intimacy in contemporary China. Asian Women 33(1), 49-71. https://doi.org/10.14431/aw.2017.03.33.1.49.

Ziegler, C. (2007). Favored flowers: Culture and Economy in a Global System (Durham, NC, U.S.A.: Duke Univ. Press). https://doi. org/10.1515/9780822390015.

Received: Jun. 16, 2020

Accepted: Jun. 22, 2021

Address of author:

Li-Chun Huang

Department of Bio-Industry Communication and

Development, National Taiwan University, No. 1, Sec. 4,

Roosevelt Rd., 10617 Taipei, Taiwan

E-mail: lihuang@ntu.edu.tw 